\title{
Analisa kinerja bongkar muat dengan lean six sigma untuk mengurangi demurrage di pelabuhan PT. Petrokimia Gresik
}

\author{
Ni'matus Syajarotul Aliyah \\ Program Studi Manajemen Bisnis, Politeknik Perkapalan Negeri Surabaya \\ Jl. Teknik Kimia, Kampus ITS, Sukolilo-Surabaya \\ syajarotulaliyah@barata.id \\ Yugowati Praharsi* \\ Program Studi Manajemen Bisnis, Politeknik Perkapalan Negeri Surabaya \\ Jl. Teknik Kimia, Kampus ITS, Sukolilo-Surabaya \\ yugowati@ppns.ac.id \\ Danis Maulana \\ Program Studi Manajemen Bisnis, Politeknik Perkapalan Negeri Surabaya \\ Jl. Teknik Kimia, Kampus ITS, Sukolilo-Surabaya \\ danis@ppns.ac.id \\ *Penulis Korespondensi
}

Submitted: Apr 3, 2019; Reviewed: Apr 7, 2019; Accepted: Apr 22, 2020

\begin{abstract}
PT. Petrochemical Gresik is one of the firms that has a terminal to be operated by own company (Terminal for Self-interest / TUKS) which supports the activity of unloading raw materials for production and loading activities to load production results. However, in carrying out its operational activities, it still causes demurrage which is a penalty that must be paid by the shipper to shipowner because it exceeds the time limit agreed in the contract of the ship. In this study, an analysis will be carried out on how to identify waste, analyze the causes of waste in the loading and unloading performance of the ship, and analyze how to minimize the factors causing demurrage in TUKS PT. Petrochemical Gresik. The research method used is lean six sigma by integrating the concept of lean process ( 7 waste) to the six sigma tools namely DMAIC (Define, Measure, Analyze, Improve, and Control). The results of the research at the define phase can be identified into twenty one CTQ (Critical to Quality) with the highest waste value, namely the internal equipment breakdown category which will only be analyzed further. Subsequently, the measurement phase is identified by the value of DPMO (Defect per Million Opportunities) and six sigma capabilities. Furthermore, the analyze phase is done by finding the root of the problem using fishbone diagrams and FMEA (Failure Mode and Effect Analysis) to attain the value of RPN (Risk Priority Number) and the highest five RPN values. One out of the five causes that are recommended to be prioritized in the handling is operators do not work according to SOP. Finally, in the improvement phase, the new SOP from the results of discussions / interviews was made with the expert judgment related to the operation of the unloading equipment at TUKS PT. Petrochemical Gresik. By this study, lean six sigma can be applied to minimize the occurrence of demurrage by PT. Petrochemical Gresik and other industrial ports.
\end{abstract}

Keywords: Demurrage; DMAIC; fishbone diagram; FMEA; lean six sigma 
Abstrak: PT. Petrokimia Gresik merupakan salah satu perusahaan yang memiliki terminal untuk dioperasikan sendiri (Terminal untuk Kepentingan Sendiri/TUKS) yang menunjang aktivitas pembongkaran bahan-bahan baku untuk produksi dan aktivitas muat untuk muat hasil produksi, namun dalam melaksanakan kegiatan operasionalnya masih menimbulkan demurrage yakni penalti yang harus dibayarkan oleh shipper ke shipowner karena melebihi batas waktu yang telah disepakati dalam kontrak kapal. Pada studi ini dilakukan analisa mengenai cara mengidentifikasi waste, menganalisa penyebab waste pada kinerja bongkar muat kapal, serta menganalisa untuk meminimalkan faktor penyebab terjadinya demurrage di TUKS PT. Petrokimia Gresik. Metode penelitian yang digunakan adalah lean six sigma adalah mengintegrasikan konsep lean process ( 7 waste) pada tools six sigma yaitu DMAIC (Define, Measure, Analyze, Improve, dan Control). Hasil dari penelitian pada tahap define dapat diidentifikasi menjadi dua puluh satu CTQ (Critical to Quality) dengan nilai waste tertinggi yaitu pada kategori internal equipment breakdown yang nantinya hanya dilakukan analisa pada kategori tersebut. Kemudian tahap measure dilakukan pengukuran nilai DPMO (Defect per Million Opportunities) dan kapabilitas six sigma. Selanjutnya tahap analyze dilakukan pencarian akar permasalahan dengan menggunakan fishbone diagram dan FMEA (Failure Mode and Effect Analysis) untuk menghasilkan besaran RPN (Risk Priority Number) dan diperoleh 5 penyebab dengan nilai RPN tertinggi, dari kelima penyebab tersebut yang direkomendasikan untuk diprioritaskan dalam penanganannya adalah operator tidak menjalankan sesuai dengan SOP. Sedangkan pada tahap improve adalah pembuatan SOP yang baru dari hasil diskusi/wawancara dengan pihak expert judgement terkait pengoperasian alat bongkar di TUKS PT. Petrokimia Gresik. Dengan adanya penelitian ini, lean six sigma dapat diterapkan untuk meminimalkan terjadinya demurrage oleh pelabuhan PT. Petrokimia Gresik maupun pelabuhan di industri lainnya.

Kata kunci: demurrage; diagram fishbone; DMAIC; FMEA; lean six sigma

\section{PENDAHULUAN}

Pelabuhan merupakan tempat kapal bersandar, berlabuh, naik turun penumpang atau bongkar muat barang yang dilengkapi dengan fasilitas keselamatan dan kegiatan penunjang pelabuhan serta sebagai penghubung dalam perdagangan lokal, regional, maupun internasional. Pelabuhan di Indonesia terdiri dari dua klaster yaitu pelabuhan umum (publik) dan pelabuhan khusus atau pelsus (Budiyanto \& Gurning, 2017). Secara praktis bentuk-bentuk pelsus yang sering ditemui adalah dermaga industrial seperti yang dimiliki oleh PT. Petrokimia Gresik. PT. Petrokimia Gresik memiliki terminal laut yang dioperasikan untuk kepentingan sendiri atau Terminal Untuk Kepentingan Sendiri (TUKS) yang menunjang aktivitas pembongkaran bahan-bahan baku untuk produksi dan aktivitas muat untuk muat hasil produksi.

Permintaan pupuk baik dari konsumen di Indonesia maupun mancanegara dilakukan oleh PT. Petrokimia Gresik melalui kerjasama dengan beberapa supplier bahan baku. Pengadaan bahan baku dilaksanakan dengan kerjasama antara perusahaan, supplier, dan ship owner untuk mengirimkan bahan baku dari lokasi supplier menuju ke TUKS milik PT. Petrokimia Gresik. Pada saat bahan baku telah sampai di lokasi TUKS, maka perusahaan akan menjalankan operasi pembongkaran menggunakan fasilitas yang tersedia di TUKS ataupun menggunakan fasilitas vessel crane yang terdapat di kapal. Proses pembongkaran (unloading) bahan baku sangat berpengaruh terhadap kecepatan perusahaan untuk dapat melaksanakan kegiatan operasionalnya. Jika proses ini tidak terlaksana secara efektif dan efisien maka berpotensi menimbulkan demurrage yang mengakibatkan terjadi pelanggaran terhadap kontrak kapal.

Demurrage merupakan penalti yang diakibatkan oleh sebuah kapal yang melibihi batas waktu berlabuh sesuai dengan jadwal yang telah ditetapkan atau biaya yang harus dibayarkan oleh shipper atau charterer ke shipowner bila melewati waktu yang telah disepakati dalam kontrak kapal (Budiyanto \& Gurning, 2017). Salah satu faktor penyebab demurrage paling banyak terjadi di PT. Petrokimia Gresik yaitu internal breakdown (kerusakan yang terjadi pada alat bongkar muat internal dalam area kerja departemen pengelolaan pelabuhan) sehingga mengakibatkan bongkar muat terhenti 106 
serta mengakibatkan terjadinya down time. Down time merupakan waktu non produktif yang disebabkan karena berhentinya suatu kegiatan akibat kerusakan mesin, kekurangan operator, atau persediaan spare parts yang terbatas.

Kerusakan alat untuk proses pembongkaran di TUKS merupakan hambatan yang harus dihindarkan guna meningkatkan efektifitas perusahaan. Motivasi dilaksanakannya penelitian ini yaitu untuk mencapai efektivitas perusahaan serta mencari strategi untuk perbaikan kinerja proses bongkar muat kapal. Strategi seperti simulasi diskrit, Total Quality Management (TQM), lean six sigma merupakan beberapa alat untuk pengendalian kualitas dan perbaikan sistem operasi yang berorientasi pada perbaikan proses (Yang \& Basem, 2008).

Dalam penelitian ini dipilih metode pengaplikasian konsep lean dan konsep six sigma. Lean merupakan proses manufaktur dalam mengurangi pemborosan (waste) atau suatu filosofi bisnis yang berlandaskan untuk meminimasi penggunaan sumber daya (termasuk waktu) dalam berbagai aktivitas perusahaan (APICS, 2011). Six Sgma berguna untuk mengurangi variasi dengan menghilangkan cacat (defect), kesalahan, serta meningkatkan efisiensi dan kualitas (Yang \& Basem, 2008).

Lean six sigma merupakan tools yang digunakan oleh perusahaan ataupun organisasi untuk mengidentifikasi dan menghilangkan pemborosan (waste) untuk mencapai enam sigma dengan cara mengalirkan produk (material, work in process, output) dan informasi menggunakan sistem tarik (pull system) dari pelanggan internal dan eksternal dalam mengejar keunggulan dan kesempurnaan yang hanya memproduksi 3.4 cacat untuk setiap satu juta kesempatan atau 3.4 DPMO (Defect Per Million Opportunities) (Syukron \& Kholil, 2013). Lean six sigma mengadopsi fase DMAIC (Define, Measure, Analyze, Improve, dan Control) yang merupakan siklus perbaikan terus-menerus untuk mengurangi cacat produksi dan variabilitas proses bersama dengan penyederhanaan proses, standardisasi, dan pengurangan pemborosan yang diintegrasikan dengan konsep lean pada setiap tahapan yang sesuai (Tannady, 2015; Nasution, 2015).

Lean six sigma merupakan gabungan konsep Lean Process dan Six Sigma. Cara penggabungan kedua metode ini adalah dengan mengintegrasikan konsep lean process pada tools six sigma, yaitu DMAIC (Define, Measure, Analyze, Improve, dan Control) sebagai kerangka perbaikan terus-menerus untuk mengurangi cacat produksi dan variabilitas proses bersama dengan penyederhanaan proses, standardisasi, dan pengurangan pemborosan. Lean Process adalah konsep yang berfokus pada menghilangkan aktivitas yang tidak mempunyai nilai tambah (non value added activity) agar proses bekerja lebih efisien. Sedangkan Six Sigma lebih menekankan pada pemuasan keinginan pelanggan dengan menghilangkan kecacatan atau ketidaksesuaian.

Lean six sigma merupakan metode perbaikan six sigma untuk menyelesaikan masalah dan peningkatan proses melalui tahap DMAIC yang diintegrasikan dengan teknik lean pada tiap tahap Define, Measure, Analyze, Improve, dan Control yang sesuai. Menurut Zaqi \& Suseno (2015), DMAIC merupakan analisis six sigma yang menjamin voice of customer berjalan dalam keseluruhan proses sehingga dapat memuaskan pelanggan. DMAIC adalah kunci pemecahan masalah six sigma.

Adapun rumusan masalah dari penelitian ini yaitu: (1) Bagaimana cara mengidentifikasi waste pada kinerja bongkar muat kapal; (2) Bagaimana cara menganalisa penyebab waste pada kinerja bongkar muat kapal, dan (3) Bagaimana cara menganalisa untuk meminimalkan faktor penyebab terjadinya demmurage. Tujuan dari penelitian ini adalah mengidentifikasi waste, menganalisa waste, dan meminimalkan faktor penyebab terjadinya demurrage. Sedangkan manfaat yang diharapkan adalah memberikan usulan perbaikan untuk diterapkan oleh perusahaan khususnya pada proses pembongkaran muatan kapal di TUKS PT. Petrokimia Gresik.

\section{METODE}

Data yang diperlukan dalam penelitian ini terdiri dari data primer yang diperoleh dengan cara pengamatan atau observasi dan mengumpulkan informasi dengan cara wawancara kepada pihak yang terkait dengan pelayanan bongkar muat. Data sekunder mengacu pada informasi yang dilakukan oleh peneliti lain yang diterbitkan dalam jurnal maupun lainnya, serta berupa catatan perusahaan dan literatur yang berhubungan dengan penelitian ini. Data-data yang diperoleh tersebut kemudian dilakukan pengolahan lebih lanjut. Langkah-langkah pengolahan data dapat dilihat pada Gambar 1 berikut: 


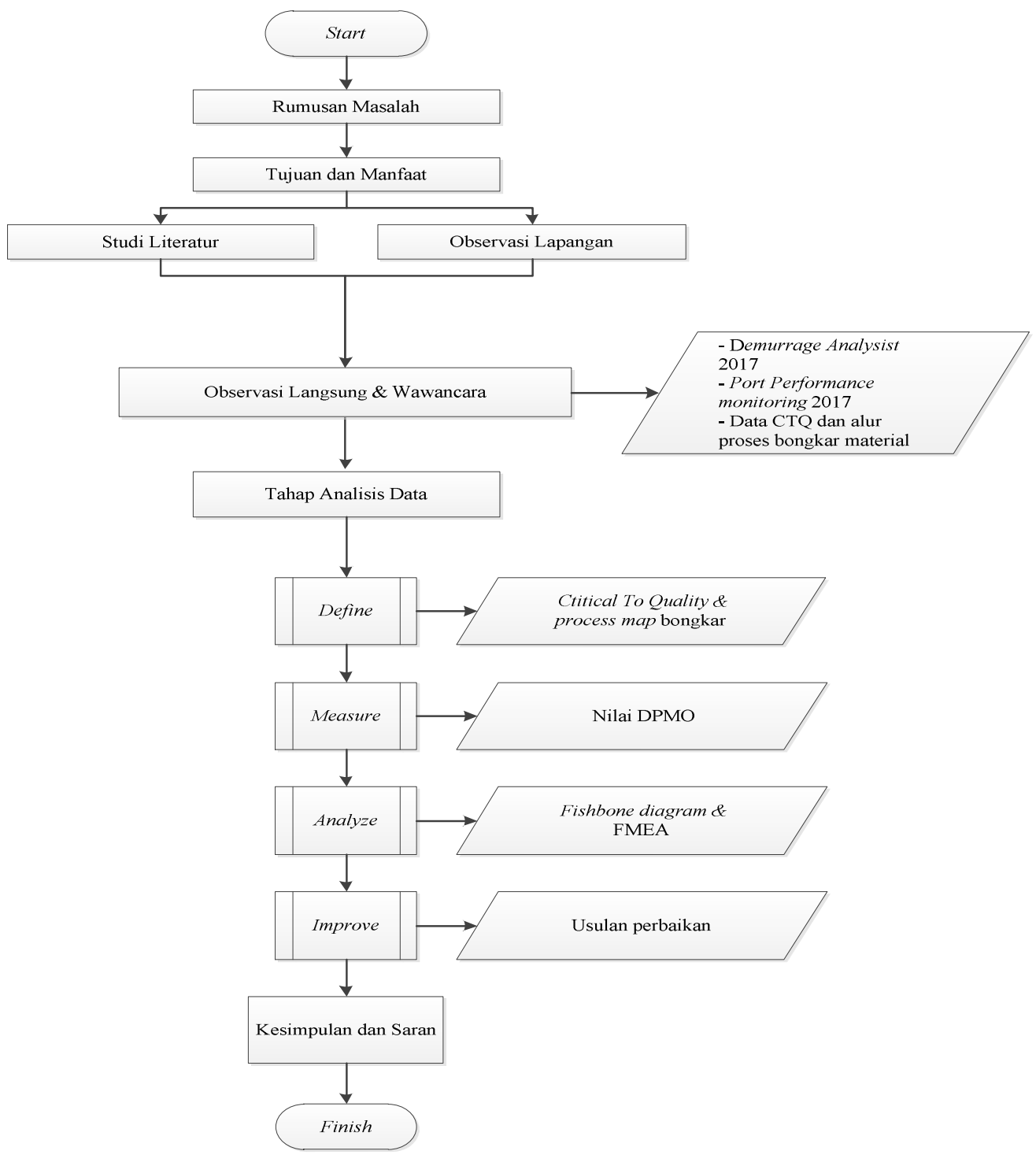

Gambar 1. Flowchart penelitian

Sumber: Hasil pengolahan peneliti di lapangan (2018)

Adapun tahapan penelitian yang dilakukan oleh peneliti adalah sebagai berikut:

1. Start

Pada tahapan awal ini dilakukan dengan observasi di PT. Petrokimia Gresik Departemen Pengelolaan Pelabuhan. Observasi awal ini dilakukan untuk memperoleh gambaran jelas mengenai permasalahan yang terjadi pada perusahaan.

\section{Melakukan Perumusan Masalah}

Setelah permasalahan teridentifikasi, maka dilanjutkan tahap perumusan masalah. Dalam penelitian ini peneliti berfokus mengenai cara meminimalkan faktor penyebab demurrage pada proses bongkar muatan kapal di TUKS PG dengan menggunakan metode lean six sigma, karena proses bongkar muatan kapal seringkali mengalami keterlambatan yang sudah tertera dalam kontrak kapal shingga diidentifikasi sebagai defect.

3. Menentukan Tujuan Penelitian

Berdasarkan rumusan masalah yang ada, penulis mendefinisikan tujuan dan manfaat penulisan baik untuk perusahaan, kalangan akademis, penelitian berikutnya, maupun bagi penulis sendiri. 
4. Melakukan Studi Literatur dan Observasi Lapangan

Studi literatur mengenai konsep dan teori metode lean six sigma serta observasi lapangan untuk mengumpulkan data yang dibutuhkan oleh peneliti baik dilakukan observasi secara langsung maupun wawancara dengan pihak yang terkait.

5. Melakukan Analisis Data pada tahapan berikut:

Tahap Define

Dimulai dengan mengidentifikasi critical to quality, dilanjutkan dengan menggambarkan proses keseluruhan dengan process map. Hal ini merupakan awal dalam upaya peningkatan proses.

Tahap Measure

Melakukan pengukuran atas permasalahan yang telah ditemukan dengan pengukuran DPMO yang kemudian dikonversikan ke kapabilitas sigma.

Tahap Analyze

Menganalisa penyebab defect dengan menggunakan diagram fishbone serta failure modes and effect analysis (FMEA).

Tahap Improve

Setelah diketahui akar penyebab permasalahan melalui diagram fishbone dan FMEA, dilanjutkan dengan usulan perbaikan pada proses bongkar muatan kapal agar tidak terjadi demurrage.

6. Memberikan kesimpulan dan saran kepada perusahaan sehingga dapat bermanfaat bagi perusahaan.

\section{HASIL DAN PEMBAHASAN}

Prinsip lean six sigma mengadopsi metode perbaikan six sigma (DMAIC) yang disinergikan dengan teknik lean pada tiap tahapan yang sesuai sebagai berikut:

1. Tahap Define

Pada tahap ini dilakukan identifikasi untuk menentukan CTQ. Dari data yang diperoleh terdapat dua puluh satu karakteristik yang temasuk kedalam CTQ, yaitu: Congestion, Cargo, Vessel Condition, Lack of Power, External Equipment Breakdown, Internal Equipment Breakdown, Unavailable Space, Unready Loading Point, Loading Hopper, Draught Survey, Preparation, Hatch Switch, Tripper Switch, Warehouse Switch, In-Out Heavy Equipment, Vessel Shifting, Trimming, Greasing, Idle Stevedore, Idle Dump Truck, dan Wait Heavy Equipment. Setelah CTQ teridentifikasi, dan ternyata harapan pelanggan masih belum dapat terpenuhi karena masih adanya waste yang terjadi. Maka tahapan awal dalam perbaikan proses dilakukan dengan menggambarkan alur proses bongkar dengan menggunakan process map seperti yang ditunjukkan pada Gambar 2.

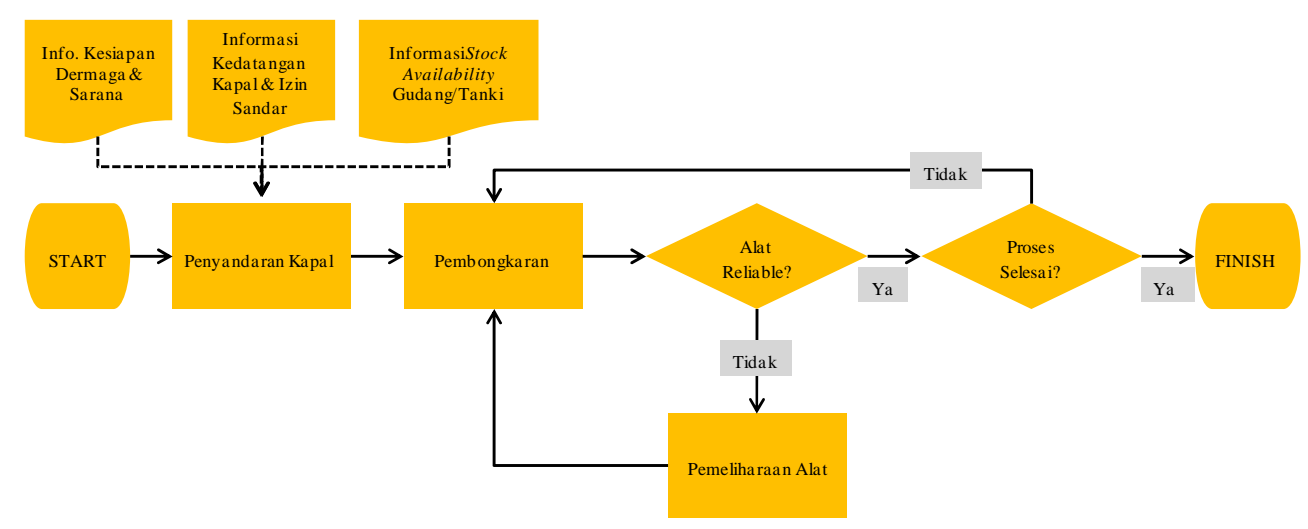

Gambar 2. Process map pembongkaran (data internal perusahaan yang telah diolah)

Sumber: Hasil pengolahan peneliti di lapangan (2018)

\section{Tahap Measure}

Tahap measure merupakan langkah kedua dalam penerapan lean sig sigma dengan model DMAIC. Pada tahap ini dilakukan pengukuran tingkat defect yang terjadi pada proses pembongkaran selama 
tahun 2017. Level kualitas (sigma) bisa dikonversikan dari DPMO ke nilai sigma berdasarkan Motorola's 6-sigma process (normal distribution shifted 1.5-sigma) (Gaspersz, 2015). Hasil perhitungan nilai DPMO dan tingkat sigma dapat dilihat dalam Tabel 1.

Tabel 1. Perhitungan nilai DPMO dan tingkat sigma

\begin{tabular}{llllll}
\hline Bulan & $\begin{array}{l}\text { Total } \\
\text { Pembongkaran }\end{array}$ & $\begin{array}{l}\text { Defect } \\
\text { (demurrage })\end{array}$ & CTQ & DPMO & SIGMA \\
\hline Januari & 15 & 4 & 21 & 12698,4127 & 3,74 \\
Februari & 9 & 1 & 21 & 5291,0053 & 4,06 \\
Maret & 10 & 2 & 21 & 9523,8095 & 3,84 \\
April & 14 & 1 & 21 & 3401,3605 & 4,21 \\
Mei & 15 & 2 & 21 & 6349,2063 & 3,99 \\
Juni & 8 & 3 & 21 & 17857,1429 & 3,60 \\
Juli & 9 & 1 & 21 & 5291,0053 & 4,06 \\
Agustus & 9 & 2 & 21 & 10582,0106 & 3,81 \\
September & 14 & 1 & 21 & 3401,3605 & 4,21 \\
Oktober & 12 & 1 & 21 & 3968,2540 & 4,15 \\
Desember & 11 & 1 & 21 & 4329,0043 & 4,13 \\
Rata-rata & 126 & 19 & 21 & 7517,51 & 3,98 \\
\hline Sumber: Hal & & & & & \\
\hline
\end{tabular}

Sumber: Hasil pengolahan data

Dari Tabel 1 dapat disimpulkan bahwa rata-rata nilai DPMO masih cukup tinggi, yaitu 7518 selama bulan Januari-Desember, yang dapat diinterpretasikan bahwa dalam satu juta kesempatan yang ada akan terdapat 7518 kemungkinan bahwa proses pembongkaran bahan baku MOP, Sulphur, dan Phospat Rock akan menghasilkan cacat.

3. Tahap Analyze

Dalam metode lean six sigma terdapat 7 waste yang harus diidentifikasi yakni (Shah \& Alad, 2016): overproduction, defect, inventory, transportation, waiting, motion, dan overprocessing.

Tabel 2. Data kategori waste

\begin{tabular}{lllr}
\hline No & Jenis Waste & Kategori & USD \\
\hline 1 & Overproduction & - & - \\
2 & Defect & External equipment breakdown & 47.532 \\
& & Internal equipment breakdown & 246.478 \\
3 & Inventory & - & - \\
4 & Transportation & In-out heavy equipment & 7.570 \\
5 & & Congestion & 39.697 \\
& \multirow{2}{*}{ Waiting } & Idle stevedore & 25.951 \\
& & Idle dump truck & 51.300 \\
& & Wait heavy equipment & 4.161 \\
6 & \multirow{4}{*}{ Motion } & Hatch switch & 50.379 \\
& & Tripper switch & 7.593 \\
7 & Overprocessing & Warehouse switch & 4.877 \\
\hline
\end{tabular}

Sumber: Hasil pengolahan data

Dari Tabel 2, faktor-faktor yang memengaruhi demurrage kategori waste tertinggi ada pada internal equipment breakdown (kerusakan yang terjadi pada alat bongkar muat internal sekaligus termasuk dalam wewenang departemen pengelolaan pelabuhan). Oleh karena itu diperlukan perbaikan dengan menghilangkan waste tersebut, selanjutnya hanya akan dilakukan analisa pada waste defect kategori internal equipment breakdown. Untuk mengetahui penyebab terjadinya waste tersebut dapat diurai pada fishbone diagram berikut: 


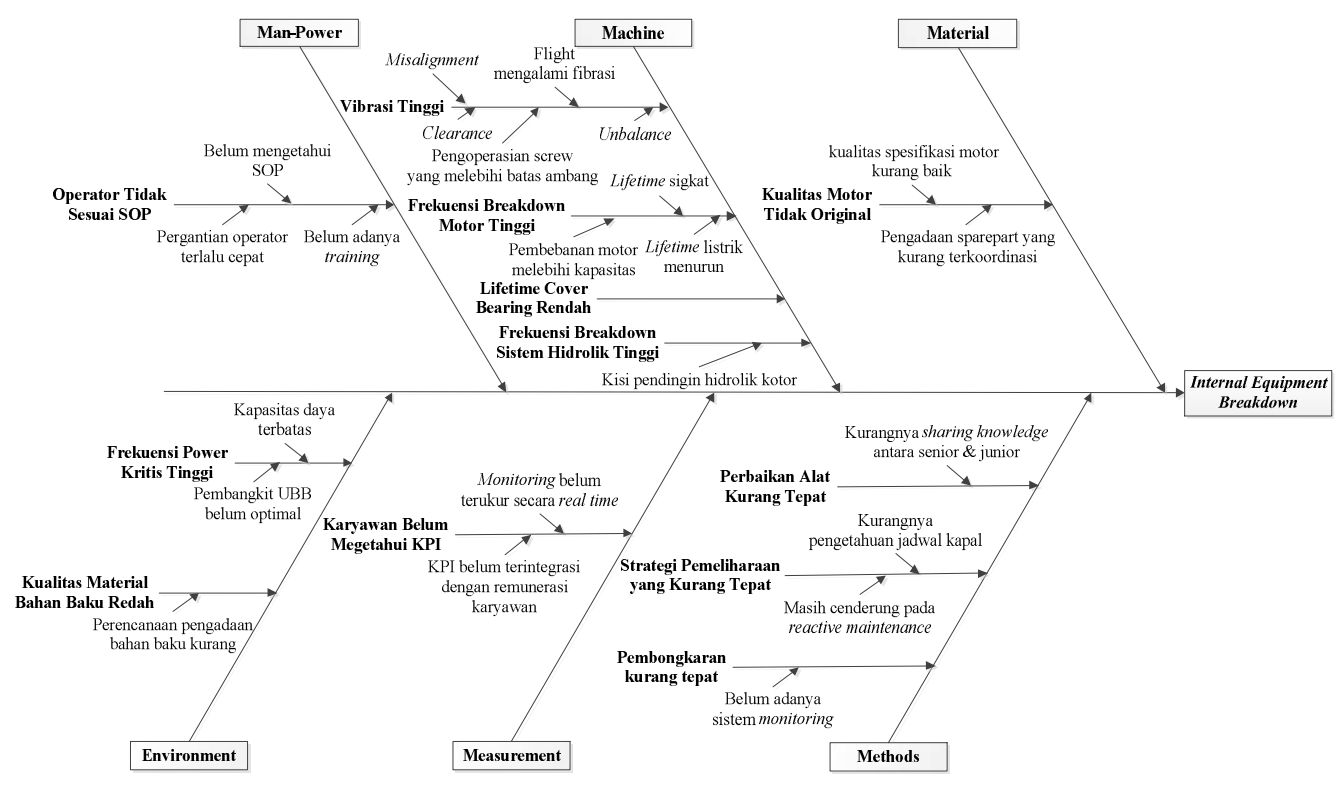

Gambar 3. Fishbone diagram dari penyebab internal equipment breakdown

Sumber: Hasil pengolahan peneliti di lapangan (2018)

Setelah diagram fishbone diketahui analisa selanjutnya dilakukan dengan menggunakan metode FMEA (Failure Mode and Effect Analysis) sehingga diperoleh besaran RPN (Risk Priority Number) sebagai berikut:

Tabel 3. Angka prioritas risiko (RPN)

\begin{tabular}{|c|c|c|c|c|c|}
\hline $\begin{array}{l}\text { Jenis } \\
\text { Kegagalan } \\
\text { Potensial }\end{array}$ & Penyebab & SEV & OCC & DET & RPN \\
\hline $\begin{array}{l}\text { Internal } \\
\text { Equipment }\end{array}$ & a. $\begin{array}{l}\text { Kualitas motor yang kurang baik (tidak } \\
\text { original) }\end{array}$ & 7 & 4 & 5 & 142 \\
\hline \multirow[t]{11}{*}{ Breakdown } & b. Vibrasi tinggi & 9 & 8 & 3 & 200 \\
\hline & c. Frekuensi breakdown motor tinggi & 7 & 5 & 4 & 169 \\
\hline & d. Lifetime cover bearing rendah & 7 & 6 & 3 & 124 \\
\hline & e. Frekuensi breakdown sistem hidrolik tinggi & 7 & 6 & 5 & 198 \\
\hline & f. Operator tidak menjalankan sesuai dengan SOP & 7 & 5 & 8 & 280 \\
\hline & g. Metode perbaikan kurang tepat & 6 & 4 & 6 & 156 \\
\hline & h. Strategi pemeliharaan yang kurang tepat & 7 & 7 & 6 & 293 \\
\hline & i. Metode pembongkaran kurang tepat & 6 & 4 & 6 & 156 \\
\hline & j. $\quad$ Karyawan belum mengetahui KPI & 4 & 6 & 5 & 146 \\
\hline & k. Frekuensi power kritis tinggi & 6 & 5 & 6 & 179 \\
\hline & $\begin{array}{l}\text { 1. Kualitas material bahan baku yang di bongkar } \\
\text { rendah/ bersifat abrasif }\end{array}$ & 7 & 7 & 5 & 245 \\
\hline
\end{tabular}

Sumber: Hasil pengolahan data

Dari analisa FMEA diketahui bahwa nilai RPN yang digunakan sebagai batasan penelitian adalah 5 penyebab dengan nilai RPN tertinggi. Batasan ini berdasarkan kesepakatan peneliti dengan departemen pengelolaan pelabuhan. Adapun 5 penyebab tersebut adalah: Pertama, strategi pemeliharaan yang kurang tepat. Kedua, operator tidak menjalankan sesuai dengan SOP. Ketiga, kualitas material bahan baku yang dibongkar bersifat abrasif. Keempat, vibrasi tinggi. Kelima, frekuensi breakdown sistem hidrolik tinggi. Dari kelima penyebab tersebut di atas yang direkomendasikan untuk diprioritaskan dalam penanganannya adalah operator tidak menjalankan sesuai dengan SOP. 


\section{Tahap Improve}

Usulan yang diberikan untuk perbaikan agar tidak terjadi internal breakdown tinggi adalah revisi SOP yang baru dalam bentuk narasi dan flowchart dengan meminta feedback dari pihak operator pengoperasian CSU (Continous Ship Unloader) yang nantinya akan diterapkan oleh pihak PT. Petrokimia Gresik setelah dirapatkan dengan pihak internal perusahaan. Gambar 4 merupakan merupakan flowchart SOP pengoperasian CSU.

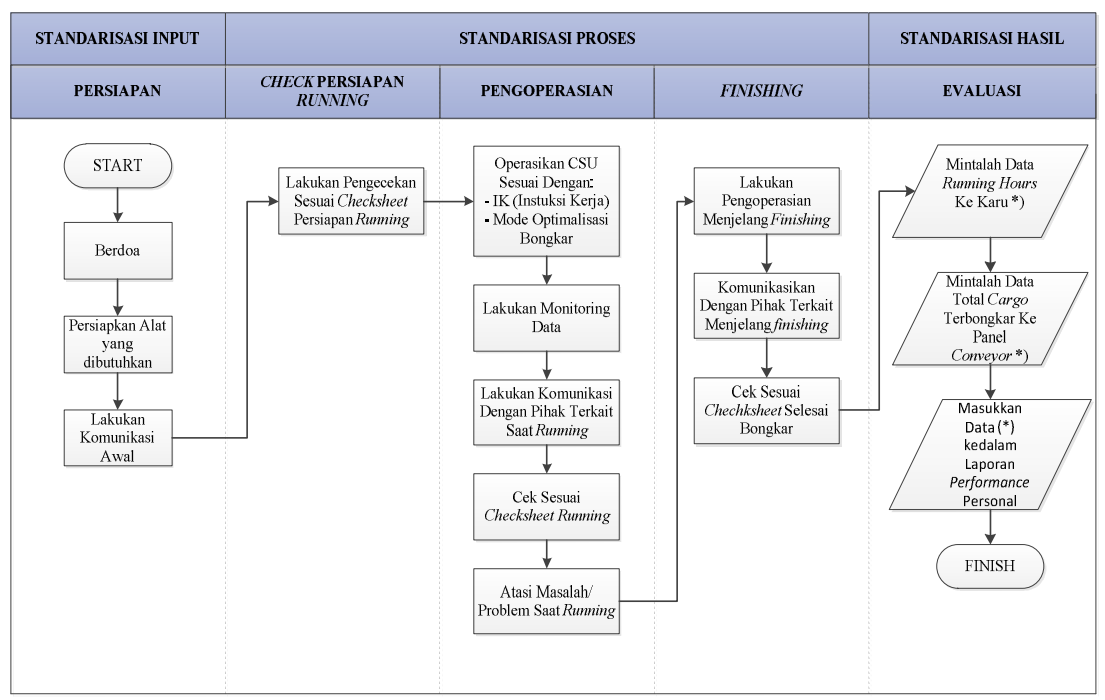

Gambar 4. Flowchart sop pengoperasian CSU

Sumber: Hasil pengolahan peneliti di lapangan (2018)

Dengan pengerjaan pada metode FMEA maka peneliti dapat memberikan usulan perbaikan pada perusahaan. Secara teknisi penetapan nilai-nilai keseriusan akibat kesalahan terhadap proses dan konsumen (severity), frekuensi terjadinya kesalahan (occurance), dan keseriusan akibat kesalahan terhadap alat control akibat potensial cause (detection) dengan jalan brainstorming. Adapun rekomendasi perbaikan yang dapat diberikan untuk kategori 5 nilai RPN tertinggi adalah sebagai berikut:

Tabel 4. Rekomendasi perbaikan yang telah dikonfirmasikan ke perusahaan

\begin{tabular}{cll}
\hline No & \multicolumn{1}{c}{ Penyebab } & \multicolumn{1}{c}{ Rekomendasi Perbaikan } \\
\hline 1 & $\begin{array}{l}\text { Strategi pemeliharaan yang } \\
\text { kurang tepat (P1) }\end{array}$ & Melakukan pemeliharaan berdasarkan running hours \\
2 & $\begin{array}{l}\text { Operator tidak menjalankan } \\
\text { sesuai dengan SOP (S2) }\end{array}$ & $\begin{array}{l}\text { Revisi SOP dengan meminta feedback dari pihak operator } \\
\text { pengoperasian CSU }\end{array}$ \\
3 & $\begin{array}{l}\text { Kualitas material bahan baku } \\
\text { yang di bongkar rendah/ } \\
\text { bersifat abrasif (P3) }\end{array}$ & $\begin{array}{l}\text { Melakukan pengecekan setiap material yang mengandung silika } \\
\text { tinggi dengan cara mempercepat perbaikan }\end{array}$ \\
4 & $\begin{array}{l}\text { Vibrasi tinggi (P4) } \\
\text { Frekuensi } \\
\text { breakdown sistem hidrolik } \\
\text { tinggi (P5) }\end{array}$ & $\begin{array}{l}\text { Pola perbaikan dengan metode predictive maintenance } \\
\text { (berdasakan time scheduling sparepart) } \\
\text { Melakukan penambahan alat seperti honeywell timer untuk } \\
\text { mengatur mekanisme pergerakan naik turunnya screw }\end{array}$ \\
\hline Sumberang
\end{tabular}

Sumber: Hasil pengolahan peneliti di lapangan (2018) 


\section{Tahap Control}

Jika pada tahap measure dapat disebut sebagai fondasi dari sebuah proyek six sigma, maka pada tahap control ini merupakan tahap yang terpenting karena perbaikan ulang terhadap proses yang tidak diingikan serta mendapatkan keuntungan dari perbaikan yang terus menerus harus didapatkan. Fase control merupakan fase untuk memantau supaya alternatif perbaikan yang terpilih benar-benar dapat diaplikasikan.

Tabel 5. Usulan pengendalian perbaikan

\begin{tabular}{|c|c|c|}
\hline Penyebab & Rekomendasi Perbaikan & Usulan Pengendalian \\
\hline $\mathrm{P} 1$ & $\begin{array}{l}\text { Melakukan pemeliharaan } \\
\text { berdasarkan running hours }\end{array}$ & $\begin{array}{l}\text { - Tolak ukur standard running hours adalah } 1000 \text { jam/ } \\
\pm 3 \text { bulan dengan standar waktu perbaikan } \pm 120 \\
\text { menit. } \\
\text { - Mengganti peralatan seperti bagian instrumen, } \\
\text { mekanik, dan listrik yang tidak berfungsi dengan baik } \\
\text { dan mengikuti sistem kerja pada setiap peralatan yang } \\
\text { tertera. }\end{array}$ \\
\hline $\mathrm{P} 2$ & $\begin{array}{l}\text { Revisi SOP dengan meminta } \\
\text { feedback dari pihak operator } \\
\text { pengoperasian CSU }\end{array}$ & $\begin{array}{l}\text { - Memberikan prosedur kerja pada operator dan } \\
\text { dijelaskan sampai operator memahami prosedur kerja } \\
\text { tersebut. } \\
\text { - Melakukan inspeksi secara rutin apakah operator } \\
\text { bekerja sesuai dengan SOP yang baru atau tidak. }\end{array}$ \\
\hline P3 & $\begin{array}{l}\text { - Harus berhubungan dengan } \\
\text { pihak pengadaan }\end{array}$ & $\begin{array}{l}\text { - Melakukan pengecekan setiap material yang } \\
\text { mengandung silika tinggi dengan cara mempercepat } \\
\text { perbaikan. }\end{array}$ \\
\hline $\mathrm{P} 4$ & $\begin{array}{l}\text { - Pola perbaikan dengan metode } \\
\text { predictive maintenance } \\
\text { (berdasakan time scheduling } \\
\text { sparepart) }\end{array}$ & $\begin{array}{l}\text { - Melakukan pergantian screw vertical, screw conveyor, } \\
\text { screw horizontal, flight bearing, dan cover bearing } \\
\text { setiap 1,5 bulan atau setiap melakukan } \\
\text { kegiatan pembongkaran } 4 \text { sampai } 5 \text { kapal. }\end{array}$ \\
\hline P5 & $\begin{array}{l}\text { - Melakukan penambahan alat } \\
\text { seperti honeywell timer untuk } \\
\text { mengatur mekanisme } \\
\text { pergerakan naik turunnya } \\
\text { screw. }\end{array}$ & $\begin{array}{l}\text { - Memberikan arahan-arahan kepada operator } \\
\text { pengoperasian CSU dengan diawali tahap sirkulasi } \\
\text { selama } 5 \text { menit, yang kedua baru tahap movement. } \\
\text { - Adanya pengawasan terhadap pelaksanaan } \\
\text { pergerakan alat, apabila terjadi masalah maka alarm } \\
\text { akan berbunyi. }\end{array}$ \\
\hline
\end{tabular}

Sumber: Hasil pengolahan peneliti di lapangan (2018)

Dari Tabel 5 di atas merupakan usulan pengendalian dari lima (5) rekomendasi perbaikan yang nantinya dapat diimplementasikan oleh pihak pelabuhan PT. Petrokimia Gresik dalam meminimalkan terjadinya demurrage.

\section{SIMPULAN DAN SARAN}

Kesimpulan yang didapatkan dari penelitian ini adalah:

1. Proses kinerja bongkar muat kapal di TUKS PT. Petrokimia Gresik dapat diidentifikasikan menjadi dua puluh satu CTQ yang meliputi: Congestion, Cargo, Vessel Condition, Lack of Power, External Equipment Breakdown, Internal Equipment Breakdown, Unavailable Space, Unready Loading Point, Loading Hopper, Draught Survey, Preparation, Hatch Switch, Tripper Switch, Warehouse Switch, In-out Heavy Equipment, Vessel Shifting, Trimming, Greasing, Idle Stevedore, Idle Dump Truck, dan Wait Heavy Equipment. Kemudian untuk mengidenifikasi masalah yang terjadi maka tahapan awal dalam perbaikan proses dilakukan dengan penggambaran proses bongkar secara keseluruhan menggunakan process map. 
2. Pada tahap analisa penyebab waste dilakukan pengukuran tingkat defect yang dinyatakan dalam DPMO dan dikonversikan dalam ukuran sigma. Setelah dilakukan pengukuran maka analisa terhadap penyebab waste tertinggi ada pada jenis waste defect yaitu kategori internal equipment breakdown (kerusakan yang terjadi pada alat bongkar muat internal sekaligus termasuk dalam wewenang departemen pengelolan pelabuhan), selanjutnya hanya dilakukan analisa pada kategori internal equipment breakdown. Pencarian akar permasalahan ditentukan dengan menggunakan fishbone diagram dan FMEA (Failure Mode and Effect Analysis) untuk menghasilkan besaran RPN (Risk Priority Number). Berdasarkan kesepakatan peneliti dengan pihak departemen pengelolaan pelabuhan diperoleh 5 penyebab dengan nilai RPN tertinggi yaitu strategi pemeliharaan yang kurang tepat, operator tidak menjalankan sesuai dengan SOP, kualitas material bahan baku yang dibongkar bersifat abrasif, vibrasi tinggi, dan frekuensi breakdown sistem hidrolik tinggi. Dari kelima penyebab tersebut yang direkomendasikan untuk diprioritaskan dalam penanganannya adalah operator tidak menjalankan sesuai dengan SOP (nilai RPN tertinggi kedua), karena untuk kategori penyebab yang lainnya terdapat beberapa yang masih sulit untuk diperbaiki.

3. Untuk meminimalkan faktor penyebab terjadinya demurrage adalah usulan perbaikan agar tidak terjadi internal breakdown tinggi yaitu dengan pembuatan SOP yang baru melalui feedback dari pihak operator pengoperasian CSU (expert judgement) yang nantinya akan diterapkan di TUKS PT. Petrokimia Gresik.

Adapun saran yang diberikan peneliti bagi perusahaan adalah:

1. Perusahaan dapat menerapkan metode lean six sigma sebagai upaya untuk meningkatkan kualitas, dapat mengetahui penyebab-penyebab kesalahan dalam proses pelayanan bongkar bahan baku secara detail, sebagai kerangka perbaikan terus-menerus untuk mengurangi cacat/ketidaksesuaian serta pengurangan pemborosan. Selanjutnya diukur nilai sigma yang baru dengan nilai sigma yang lebih besar, sehingga dapat mengendalikan proses pelayanan bongkar dan demurrage dapat diminimalkan dengan baik.

2. Pemilihan CTQ dapat diperluas dengan variabel-variabel yang lain seperti: kategori NVABN (draught survey, preparation, hatch switch, tripper switch, warehouse switch, in-out heavy equipment, vessel shifting, trimming, dan greasing); kategori NVA (idle stevedore, idle dump truck, dan wait heavy equipment); serta kategori external equipment breakdown.

\section{REFERENSI}

APICS. (2011). Operations Management Body of Knowledge Framework. $3^{\text {rd }}$ Edition. Chicago: APICS The Association for Operations Management

Budiyanto, E.H., \& Gurning, R.O S. (2017). Manajemen Pelabuhan (Pasca UU No. 17 Tahun 2008Era Poros Maritim \& Tol Laut). Surabaya: PT. Andhika Prasetya Ekawahana

Gaspersz, V. (2015). The Executive Guide to Implementing Lean Six Sigma. Jakarta: Gramedia Pustaka Utama

Nasution, N.M. (2015). Manajemen Mutu Terpadu. Edisi Ketiga. Bogor: Ghalia Indonesia

Shah, A.Y., \& Alad, B.A. (2016). Lean Tools for Productivity Improvement-A Review. REST Journal on Emerging Trends in Modelling and Manufacturing, Vol.2 (4), pp. 114-118

Syukron, A., \& Kholil, M. (2013). Six Sigma Quality for Business Improvement. Yogyakarta: Graha Ilmu

Tannady, H. (2015). Pengendalian Kualitas. Yogyakarta: Graha Ilmu

Yang, K., \& Basem, E.H (2008). Design for Six Sigma: a Roadmap for Product Development. $2^{\text {nd }}$ Edition. USA: McGraw-Hill

Zaqi, A.A.F., \& Suseno. (2015). Peningkatan Produktivitas Perusahaan dengan Menggunakan Metode Six Sigma, Lean, dan Kaizen. Jurnal Teknik Industri Universitas Teknologi Yogyakarta, Vol 10(2) 